\title{
PSICOLOGIA E FILOSOFIA NA ABORDAGEM FENOMENOLÓGICO-EXISTENCIAL: UM ESTUDO SOBRE FRANKL E HEIDEGGER
}

\author{
Psychology and philosophy in the existential-phenomenological approach: a study on Frankl and Heidegger
}

Psicología y filosofia en el enfoque fenomenológico-existencial: un estudio sobre Frankl y Heidegger

MARCELO VIAL ROEHE

Resumo: A obra do filósofo Martin Heidegger é determinante para o desenvolvimento da psicologia fenomenológico-existencial. Apesar disso, é reconhecida a dificuldade para sua compreensão e adaptação aos objetivos da psicologia. Este estudo propõe uma exemplificação de como noções heideggerianas podem ser trabalhadas na psicologia, aproximando-as do pensamento do psiquiatra Viktor Frankl. Ainda que tenha estudado sua filosofia, Frankl não fundamentou seu trabalho na obra de Heidegger, no entanto, os conceitos principais de sua Logoterapia permitem que se pense em possibilidades de desdobramento psicológico da Analítica do Dasein. Da parte de Frankl, as ideias de autotranscendência, sentido de vida, valores, noodinâmica e frustração existencial são discutidas como implicações psicológicas do Dasein heideggeriano, com atenção a noções como ser-no-mundo, poder-ser, possibilidade e disposição afetiva.

Palavras-chave: Frankl; Logoterapia; Heidegger; Psicologia Fenomenológico-Existencial

\begin{abstract}
Martin Heidegger's philosophical work is decisive to existential-phenomenological psychology's development. Despite this it has been considered difficult to understand and to apply at the psychological level. This study exemplifies how heideggerian ideas can be of use in psychology by approaching them to Viktor Frankl's Logotherapy. Though Frankl had studied the philosopher's work, his theory is not primarily based on Heidegger's Dasein Analytic. In this article, Logotherapy's key concepts are discussed as a possibility of Heidegger's analytic psychological understanding. Frankl's concepts like self-transcendence, meaning of life, values, noodynamics and existential frustration are presented as psychological implications of Heidegger's existential structures like being-in-the-world, potentiality of being, possibility, and disposition.
\end{abstract}

Keywords: Frankl; Logotherapy; Heidegger; Existential-Phenomenological Psychology.

Resumen: El trabajo filosófico de Martin Heidegger es decisivo para el desarrollo de la psicología fenomenológico-existencial. Sin embargo, se ha considerado difícil de entender y de aplicar a la psicología. Este estudio ejemplifica cómo las ideas heideggerianas pueden ser de utilidad en psicología acercándolas a la Logoterapia de Viktor Frankl. Aunque Frankl haya estudiado el trabajo del filósofo, su teoría no se basa principalmente en la Analítica del Dasein. En este artículo, los conceptos clave de la Logoterapía se discuten como una posibilidad de la comprensión psicológica de la Analítica de Heidegger. Los conceptos de Frankl como la autotrascendencia, el sentido de la vida, los valores, la noodinámica y la frustración existencial se presentan como implicaciones psicológicas de las estructuras existenciales presentadas por Heidegger, como ser-en-el-mundo, poder-ser, posibilidad y disposición afectiva.

Palabras-clave: Logoterapía; Heidegger; Psicología Fenomenológico-Existencial.

\section{Introdução}

A psicologia fenomenológico-existencial (F-E) é fruto da influência exercida por filósofos sobre psiquiatras e psicólogos, a partir da primeira metade do século XX. Se, por um lado, os profissionais da área "psi" encontraram na filosofia ideias que lhes permitiram renovar o entendimento a respeito do ser humano, da prática clínica e da pesquisa, por outro lado, foram obrigados a lidar com a dificuldade para compreender propostas filosóficas, elaboradas para fins completamente diversos do trabalho em psicologia.
Halling e Nill (1995) observam que a psicologia F-E não é um conjunto unificado de pensamento, que se desenvolveu a partir de uma única origem. Filósofos como Soren Kierkegaard, Edmund Husserl, Martin Heidegger, Jean Paul Sartre e Maurice Merleau-Ponty aparecem, com maior ou menor ênfase, como referência para os estudos de profissionais que, por sua vez, desenvolvem diferentes compreensões desses autores.

Este trabalho visa discutir uma possibilidade de apropriação de noções filosóficas pela psicologia. Aspectos da Logoterapia de Viktor Frankl (1905-1997) serão cotejados com noções da filoso- 
fia fenomenológico-existencial de Martin Heidegger (1889-1976). Entende-se que Heidegger ofereceu, embora involuntariamente, a mais influente concepção de homem no campo da psicologia F-E. Frankl, por sua vez, ainda que tivesse contato pessoal com o filósofo e utilizasse o "nome alternativo" Análise Existencial para seu pensamento (Frankl, 2000), não caracterizou sua teoria como diretamente vinculada ao pensamento de Heidegger; ao contrário, por exemplo, de Medard Boss (que contou com a colaboração do filósofo) e do pioneiro Ludwig Binswanger.

Binswanger (1881-1966), por pioneiro que foi na apropriação da filosofia de Heidegger para a compreensão psiquiátrica, inaugurou a dificuldade de transpor a filosofia para a psicologia/psiquiatria. Vide o conhecido episódio, assumido pelo próprio Binswanger, do "produtivo mal-entendimento" do pensamento de Heidegger (Frie, 1999). É em vista desse episódio e de outras menções à dificuldade que o texto de Heidegger impõe aos interessados em seu pensamento (Cerbone, 2009; Horrigan-Kelly, Millar \& Dowling, 2016), que o artigo se desenvolve.

Pretende-se mostrar como alguns dos conhecidos termos heideggerianos podem ser compreendidos, em sua aproximação à psicologia. Para isso, toma-se uma teoria já estabelecida, a Logoterapia de Frankl, e estabelece-se uma aproximação entre os conceitos psicológicos deste e as noções fenomenológico-existenciais do filósofo. Parte-se do princípio de que o nível de questionamento filosófico fundamenta o nível psicológico, ou seja, a título de exemplo, o ser-no-mundo de Heidegger como condição para a elaboração de uma psicologia não-mentalista, que valorize o ser humano como relacionado ao que é diferente de si mesmo.

A aproximação entre Frankl e Heidegger é uma proposta do autor. Não se está atribuindo ao trabalho de Frankl qualquer vínculo ou dependência conceitual para com a filosofia de Heidegger.

\section{A Analítica fenomenológico-existencial de Heidegger}

Se a linguagem filosófica já é difícil para quem não é filósofo, mais ainda uma filosofia (a de Heidegger) que pretende rever a linguagem filosófica anterior. A impressão que fica é de que quem recorre a Heidegger, do ponto de vista da psicologia, está sempre prestes a se equivocar. Para um psicólogo, como Letteri (2009): "Os escritos de Heidegger frequentemente geram desorientação que, por vezes, chega ao desespero. Não-filósofos comumente estão em conflito com a densidade de sua linguagem” ( $p$. xiii).

Quando se afirma que a contribuição fundamental de Heidegger para o desenvolvimento da psicologia F-E, foi uma involuntária concepção de homem, já se está caracterizando a dificuldade de apropriação de sua filosofia. O projeto filosófico de Heidegger, iniciado em sua obra Ser e Tempo (Heidegger, 1927/2006) consistia no questionamento do ser, ou seja, a abertura que torna possível conside- rar algo como isto ou aquilo e, assim, dar sentido ao que se mostra (Sheehan, 2014).

Como ponto de partida para o questionamento do ser, Heidegger elege o ente que, em seu ser, apresenta a possibilidade de questionar: o ente que nós mesmos somos. Já tendo em vista a investigação desse ente em seu ser, a fim de estabelecer uma discussão com a tradição metafísica a respeito do ser em geral, Heidegger chama o ente que nós somos de Dasein. Denominações como "homem", "sujeito", "animal racional" são produto do pensamento metafísico, o qual o filósofo coloca em questão. Com os próprios termos empregados, Heidegger pretende rever a tradição metafísica, cuja linguagem carrega consigo as consolidações que o filósofo visa evitar. A Analítica Existencial ou Analítica do Dasein é a descrição fenomenológica do modo de ser do ente que nós mesmos somos.

$\mathrm{Na}$ diferenciação entre ser e ente tem-se dois níveis: o ontológico (ser), no qual se dá atenção às condições de possibilidade para que um ente se manifeste ou para como um ente vem a nossa presença e o ôntico (ente), no qual a atenção se dirige para as características de um ente qualquer ou para o modo de ser daquilo que já está presente. Lembre-se que a reprovação de Heidegger ao pensamento de Binswanger deu-se em torno desse ponto (Heidegger, 1987/2001). No nível ôntico, estuda-se o modo de ser dos entes; no ontológico, as condições para que os entes possam ser. Heidegger desenvolve a Analítica do Dasein no nível ontológico, ou seja, não visa o "homem", porém as condições ontológicas que possibilitam ao ente que nós mesmos somos compreender-se como homem.

A descrição do modo de ser do Dasein seria a primeira etapa do questionamento do ser em geral; projeto este que, do ponto de vista de Ser e Tempo, ficou inconcluso, uma vez que a aventada segunda parte da obra nunca foi publicada (Mulhall, 2013). Essa descrição - ontológica -, entretanto, atraiu a atenção de profissionais do campo psicológico/ psiquiátrico na forma de uma nova concepção de homem, dissociada das analogias naturalistas, do dualismo sujeito-objeto e das relações mecânico-funcionais com o ambiente.

Desse modo, uma etapa do trabalho (ontológico) de Heidegger, veio a se tornar a base (ôntica) de uma abordagem psicológica. Por que ôntica? Porque os questionamentos específicos de uma ciência não têm abrangência ontológica: "O questionar ontológico é mais originário do que as pesquisas ônticas das ciências positivas" (Heidegger, 1927/2006, p. 46-47). O questionamento ontológico não se prende às especificidades de nenhuma área científica. Ele transpassa todas as ciências, propondo-lhes um fundamento. É inviável, por conseguinte, que o pensamento de uma disciplina científica faça observações que dizem respeito à fundamentação de todas as ciências.

Esta apropriação ôntica da Analítica heideggeriana, contudo, é justificada por observações do próprio Heidegger. O filósofo escreve que "A analítica existencial, por sua vez, possui, em última instância, raízes (...) ônticas" (Heidegger, 1927/2006, p. 50, 
itálicos no original), ou seja, o nível em que atuam as ciências, despreocupadas de suas condições ontológicas. Embora a Analítica seja do Dasein, entendido como o "ente que cada um de nós mesmos sempre somos” (Heidegger, 1927/2006, p. 42), Heidegger não evita completamente o termo "homem". Ele o emprega, por exemplo, deixando claro que ao "homem" atribui o modo de ser do Dasein: "como atitude do homem, as ciências possuem o modo de ser desse ente (homem). Apreendemos terminologicamente esse ente como presença" ${ }^{\text {(Heidegger, }}$ 1927/2006, p. 47, itálicos no original).

O emprego da Analítica no nível de suas "raízes ônticas" e no campo da psicologia se justifica na própria história do filósofo. Heidegger colaborou com o psiquiatra suíço Medard Boss (1903-1990) no desenvolvimento da Daseinsanalyse, uma abordagem psicoterapêutica (ôntica, portanto) baseada em sua filosofia. A participação de Heidegger na Daseinsanalyse está registrada em Seminários de Zollikon (Heidegger, 1987/2001), onde se lê, por exemplo: “(...) a relação de daseinsanalistas e analisando pode ser vivida como uma relação de Dasein para Dasein” (p. 150), afirmação na qual Heidegger situa o Dasein no nível ôntico. Assim também quando se refere a "um determinado Dasein existente" (p. 151) e ao "Dasein social-histórico e individual" (p. 151).

A Analítica de Heidegger é uma obra extensa, cuja síntese não cabe nos limites deste estudo. Além disso, seus pontos de interesse, neste artigo, são aqueles que permitem o diálogo com aspectos da obra de Viktor Frankl. Sendo assim, na sequência do artigo apresentam-se pontos da Analítica que serão colocados em relação com ideias de Frankl.

Para Heidegger (1927/2006), a descrição fundamental do ser humano é como ser-no-mundo, ou seja, não há dualismo, polaridade ou oposição entre homem e mundo: ser-homem é indissociável do mundo: “A expressão composta ‘ser-no-mundo', já na sua cunhagem, mostra que pretende referir-se a um fenômeno de unidade" (Heidegger, 1927/2006, p. 98, itálicos no original). Mundo é o que se mostra nas relações que o Dasein estabelece com os entes que vêm ao encontro. Não se trata, portanto, de um espaço no qual o ser humano se localiza, como se um objeto estivesse contido dentro de outro.

No "Aí”, os demais entes aparecem para o Ser-aí. O "Aí" é abertura relacional. Esse aparecer dos demais entes não é contemplativo, é prático. Agimos ou nos comportamos em relação aos demais entes. O comportamento ocorre conforme atribuímos significados aos demais entes. Por exemplo: usa-se microfones visando-se comunicação com outras pessoas num espaço específico. Ao microfone agregam-se um amplificador, um sistema de energia, talvez um fio. Este conjunto de entes é necessário para que cada ente revele sua relação com os demais e, finalmente, a relação do todo com uma finalidade do ser humano.

A lida cotidiana não se detém diretamente nos utensílios em si mesmos. Aquilo com que primeiro se ocupa (...) é a obra a ser produzida. É a obra que sustenta a totalidade das referências na qual o instrumento vem ao encontro. (...) Com a obra, portanto, não se dá ao encontro apenas um ente manual, mas também entes que possuem o modo de ser do homem, para os quais o produto se acha à mão na ocupação (Heidegger, 1927/2006, p. 118-119).

O encontro com os entes pressupõe um modo de ser que permita "encontrar"; sendo abertura para o ser, o Dasein habita o mundo como algo que lhe é familiar: "Essa familiaridade é enquanto tal familiaridade em um mundo" (Heidegger, 2012, p. 437, itálicos no original). As relações, por sua vez, não ocorrem a partir da racionalidade interiorizada, mas na preocupação com outros seres humanos e na ocupação com entes não humanos.

Sendo-no-mundo, o Dasein é afetado pelo encontro com os demais entes e, uma vez afetado, existe sempre em tonalidades afetivas que caracterizam as diversas relações que estabelece. Está-se falando do que Heidegger chama de disposição afetiva. O filósofo observa que a disposição é "o mais conhecido e o mais cotidiano, a saber, o humor (...)" (Heidegger, 1927/2006, p. 193). O humor diz respeito a como alguém está, "como vai”. A afetividade, o poder-ser-afetado, direciona o Dasein; os entes que se mostram para o ser humano, já aparecem vinculados a tonalidades afetivas. Afetivamente disposto, o ser humano sempre percebe os entes de algum modo ou nem mesmo chega a perceber determinados entes, pois a desatenção ou o desinteresse são, também, disposições afetivas.

O Dasein existe sempre em função de um poder-ser que, embora ainda não realizado, já o caracteriza de fato. $\mathrm{O}$ futuro (porvir) está sempre implicado, constitui as ações presentes, uma vez que o ser humano antecede-a-si-mesmo (Heidegger, 1927/2006).

Em seu ser, a presença já sempre se conjugou com uma possibilidade de si mesma (...) já sempre antecedeu a si mesma. A presença já está sempre 'além de si mesma', não como atitude frente aos outros entes que ela mesma não é, mas como ser para o poder-ser que ela mesma é (Heidegger, 1927/2006, p. 258-259, itálicos no original).

O Dasein não se define pelo que é "aqui e agora”, como um objeto restrito à sua manifestação material-presente, pois o poder-ser faz parte da sua facticidade. O que o ser humano é abrange a dimensão do possível, do ainda não que poderá vir a ser. Aquilo que o Dasein ainda não é como fato, como realidade, ele é como possibilidade, ele é existencialmente, uma vez que o ser humano é suas possibilidades. "Enquanto projeto, compreender é o modo de ser da presença em que a presença é as suas possibilidades enquanto possibilidades" (Heidegger, 1927/2006, p.206).

Antecedendo-a-si-mesmo, projetando-se em possibilidades de seu próprio ser, o Dasein tem uma relação com o seu próprio ser: "Em seu ser, isto é, sendo, este ente se relaciona com o seu ser" (Heidegger, 1927/2006, p.85). O ser do Dasein está em 
questão para ele mesmo. Não se trata, todavia, de uma questão racionalizada que gera uma resposta elaborada, conclusiva; é uma questão/relação que se "conclui" de modo provisório, a cada momento, no fazer cotidiano, ou seja: "a presença se entrega à responsabilidade de assumir seu próprio ser" (Heidegger, 1927/2006, p.85).

Heidegger retoma a relação que o Dasein tem com seu próprio ser quando chama a totalidade estrutural do Dasein como cura. A totalidade é composta por anteceder-a-si-mesmo, facticidade e ser-junto aos demais entes. Antecedendo-a-si-mesmo, o ser humano se projeta em possibilidades, a partir da situação em que ele já está e vem sendo, enquanto se preocupa com outros seres humanos e se ocupa com entes não humanos. Nos momentos constitutivos da cura, aparece a temporalidade do modo de ser humano: antecede-se (futuro), desde onde já se está (passado), a fim de lidar com o que vem ao encontro no mundo (presente).

De acordo com Borges-Duarte (2010) a cura é "inquieta atenção e tensão vital, que gere esforçada e, tantas vezes, molesta o viver, que o tempo marca e determina” (p. 120). Polt (1999) considera que existir como cura significa que seu próprio ser e o ser dos demais entes fazem diferença para o homem; Polt entende que se trata de uma reprovação implícita de Heidegger às filosofias que isolam o homem do tempo e do espaço: "não há como evitar o enraizamento num passado e o enfrentamento de um futuro" (Polt, 1999, p. 79).

\section{Frankl e Heidegger}

Na sequência do artigo, apresentam-se ideias de Frankl e retomam-se noções heideggerianas, a fim de explicitar uma possível relação entre a concepção filosófica de ser humano, como Dasein, e a proposta logoterapêutica. Ressalte-se que com essa aproximação não se pretende impor ao pensamento de Frankl uma fundamentação heideggeriana, mas sim propor uma aproximação, a fim de mostrar como a filosofia de Heidegger pode ter desdobramentos na psicologia.

A Logoterapia de Frankl teve suas origens em Viena no final dos anos 1920 (Etcheverry, 1990), como contraposição às teorias de Freud e Adler. Enquanto para este a motivação primeira do homem é a vontade de poder; para aquele trata-se da vontade de prazer. Frankl entende que a motivação fundamental do ser humano é a vontade de sentido (Frankl, 1993).

Conforme Längle (1992), sentido pode ser entendido como um modo específico de dar forma à situação. Viver com sentido quer dizer, então, que o homem, com suas disposições e aptidões, suas emoções e sua vontade, se ponha a serviço da proposta de cada hora, se confronte criativamente com ela, recebendo e dando ao mesmo tempo. Sentido é uma espécie de engajamento, de "estar totalmente dedicado a uma causa” (Längle, 1992, p.13).

Ao contrário do que se possa pensar, o sentido da vida não é uma especulação abstrata, é uma rea- lização concreta no mundo. O sentido não é definitivo (pode mudar a todo momento), nem universal (é relativo a cada pessoa). Frankl (1986) afirma que o caminho para o sentido é a realização de valores. Estes são de três tipos:

Criativos - dar algo ao mundo, uma tarefa, uma obra, um trabalho;

Vivencias - receber algo do mundo, a experiência do amor, por exemplo;

Atitudinais - posicionar-se diante do sofrimento inevitável.

À realização da vontade de sentido, Frankl associa a característica humana da autotranscendência, que significa que ser homem é estar em relação com ou orientado para qualquer coisa diferente de si próprio (Frankl, 1989). Em outras palavras, do próprio Frankl: "Quero salientar que o verdadeiro sentido da vida deve ser descoberto no mundo, e não dentro da pessoa humana ou de sua psique, como se fosse um sistema fechado" (Frankl, 1993, p. 99).

Se o homem é voltado para coisas diferentes dele próprio e o sentido é descoberto no mundo, então o ser humano deve ser aberto para o mundo e, nessa abertura, ultrapassar a si mesmo encontrando aquilo que lhe é diverso. Heidegger, em sua Analítica do Dasein, apresenta uma compreensão do modo de ser humano em que o homem não apenas transcende a si mesmo: ele é transcendência e encontro: “(...) o Da em Ser e Tempo não significa a definição de um lugar para um ente, mas deve indicar a abertura onde os entes podem estar presentes para o ser humano e o próprio ser humano presente para si mesmo" (Heidegger, 1987/2001b, p. 120, itálicos no original).

O Da de Dasein (o Aí do Ser-aí) faz parte do modo de ser humano. Não se trata portanto da possibilidade de abrir-se, pois se assim fosse haveria a possibilidade de fechar-se, ou seja, a possibilidade do não aparecimento de ente algum ou a possibilidade do não estabelecimento de relação alguma (nem consigo mesmo). Se assim fosse, não se constituiria o Da-Sein.

Sendo abertura, o ser humano vai ao encontro dos demais entes, transcendendo-se: "Ser transcendente, isto é, ser aquele que atravessa e ultrapassa, é algo que só os 'sujeitos' podem ser, os 'sujeitos' no sentido ontologicamente bem compreendido do Ser-aí" (Heidegger, 2012, p. 433) "A transcendência, o 'para além de' do Ser-aí, permite que ele se comporte em relação ao ente enquanto ente, seja esse o ente presente à vista, os outros ou si mesmo" (Heidegger, 2012, p. 436).

As relações que o ser humano estabelece com os entes constituem o mundo. $\mathrm{O}$ mundo, portanto, é um espaço existencial aberto pela transcendência do Dasein. É existencial, porque é relativo à existência, o modo de ser do Dasein; não é, então, um espaço material, geométrico. Como existência, o Dasein está colocado fora (ex-sistência) de si mesmo, junto 
aos demais entes que encontra, já que transcende, ultrapassa a si mesmo. Transcendendo a si mesmo, abre o espaço existencial que é o mundo, na forma de relações de ocupação, com entes não humanos e de preocupação, com entes humanos (Heidegger, 1927/2006). O Dasein, assim, é-no-mundo, visto que não há um Eu autossuficiente, cujo modo de ser prescinda dos demais entes ou cuja autocompreensão se desenvolva sem a identificação com as ocupações e as preocupações relativas a estes entes.

A concepção de ser humano de Heidegger (1927/2006) permite que se pense na autotranscendência proposta por Frankl, assim como na consequente relação com aquilo que é diferente de si mesmo. A autotranscedência é possível, uma vez que o ser humano é-no-mundo; o mundo é o "para onde" da autotranscendência. É-no-mundo na forma de relações com o que lhe é diferente, ou seja, não se trata de presença física em um espaço. As relações fazem parte do modo de ser humano; com o quê ou com quem se relaciona e como se relaciona são possibilidades que, veremos na sequência, podem ("poder-ser") oferecer sentido. Vattimo (1971/1987) sintetiza o pensamento elaborado até aqui: "o ser do homem consiste em estar referido a possibilidades; mas concretamente este referir-se efetua-se não num colóquio abstrato consigo mesmo, mas como existir concretamente num mundo de coisas e de outras pessoas" (p. 26)

Para Frankl, somente quando transcende a si mesmo é que o ser humano pode realizar sua vontade de sentido. $\mathrm{O}$ sentido é descoberto por meio da realização de valores. Os valores frankleanos implicam relação com o mundo: dar algo ao mundo, receber algo do mundo e posicionar-se diante do sofrimento inevitável. Neste último caso - valores de atitude - mantém-se a relação de mundo, uma vez que "este ente se relaciona com o seu ser" (Heidegger, 1927/2006, p.85). Essa relação é mundana, quer dizer, o ser humano encontra a si mesmo no mundo, ou seja, encontra-se sendo nas ocupações e nas preocupações. Portanto, encontra seu próprio ser na autotranscendência.

Conforme Heidegger (2012), o Dasein "tem em certa medida seu próprio ser na mão, à proporção em que se comporta de um modo ou de outro em relação ao seu poder-ser (...)” (p. 401). Somente há possibilidades, portanto, para o ente que se relaciona com seu ser, para o ente cujo modo de ser é poder-ser. Do contrário, as ações ou o comportamento não seriam em função de possibilidades, seriam automatizados, predeterminados, naturalizados.

Frankl (1993) afirma que: "O sentido da vida difere de pessoa para pessoa, de um dia para outro, de uma hora para outra. O que importa, por conseguinte, não é o sentido da vida de um modo geral, mas antes o sentido específico da vida de uma pessoa em dado momento" (p. 98). Com esta observação, Frankl permite que se pense na indeterminação da vida humana, em seu aspecto situacional e em sua característica mutante. A vontade de sentido decorre da indeterminação, do contrário a questão do sentido não surgiria. É preciso que o modo de ser apresente indeterminação, para que se possa ques- tionar um direcionamento. A respeito da indeterminação do ser humano, Heidegger (1927/2006) escreve: "Ser é o que neste ente está sempre em jogo" (p. 85, itálicos no original). Ou, de acordo com Blattner (2006): "nosso ser está em questão para nós" (p. 37). O ser humano, enquanto é possível, está por ser feito, por ser realizado.

Safranski (2005) observa, sobre essa característica do modo de ser humano: "no meio das coisas ele tem 'jogo', como a roda tem de ter 'jogo' no eixo para poder mover-se” (p. 359). O estar em jogo do ser humano diz respeito ao que está em aberto, às possibilidades nas quais sempre se projeta: "designamos a estrutura ontológica essencial do 'estar em jogo' como o anteceder-a-si-mesmo da presença” (Heidegger, 1927/2006, p. 259, itálicos no original). Antecede a si mesmo, porque existe projetado, ou seja, em função de possibilidades que, como tais, poderão ou não vir a ser concretizadas. É nesta indeterminação, neste estar em aberto do modo de ser humano, que Heidegger situa o "estar em jogo".

Dada a indeterminação do ser humano, a vontade de sentido é um modo de autodeterminação, é um direcionamento que o homem elege, pois é livre para determinar-se. Para que haja um sentido no mundo, é necessário que o próprio modo de ser enseje ser de um jeito ou de outro, permita escolher, decidir. Se assim é, o mundo já deve estar presente nesse modo de ser, como um horizonte de possibilidades que se mostram nos modos em que o homem se relaciona com as coisas (DeLancey, 2006).

Dasein é confrontado com possibilidades e é da sua própria natureza estar consciente dessas possibilidades em algum sentido, realizar algumas delas e rejeitar outras. Entretanto, isto não é, apenas, um modo de escolher entre opções, mas sim a constituição mesma do Dasein (DeLancey, 2006, p. 362).

Decorrem, portanto, do próprio modo de ser do homem, descrito por Heidegger, as condições para que se entenda a autotranscendência em direção ao que é diferente de si mesmo e, nessas relações, o aparecimento de possibilidades de ser de um jeito ou de outro. Projetar-se em possibilidades e, nessa projeção ou antecipação de si mesmo, fazer escolhas, é possível porque o ser humano já-é-no-mundo; o mundo como um contexto de possibilidades que se revelam na relação que o homem estabelece com os demais entes.

A respeito do homem, Frankl (1986) escreve: "a sua realidade é uma possibilidade, e o seu ser é um poder-ser" (p. 121). E acrescenta: "em nenhum instante da sua vida, pode o homem esquivar-se à forçosa necessidade de escolher entre as possibilidades" (p. 121-122). Escolher entre possibilidades é uma característica do modo de ser do homem, entendido como Dasein: "As características constitutivas da presença são sempre modos possíveis de ser e somente isso" (Heidegger, 1927/2006, p. 85).

Längle (1992) reforça a ideia da autotranscendência indeterminada do homem quando afirma 
que a questão do sentido adquire relevância, tendo em vista três experiências básicas do ser humano: o livre-arbítrio, que permite escolher entre possibilidades; o sentimento de que aquilo que é escolhido faz diferença, pois se tratam de valores e a inconstância das situações, sempre em transformação.

A posição de Längle oportuniza propor uma transição, psicológica, das possibilidades para os valores. No nível da consideração ontológica, o ser humano é suas possibilidades, sem que isso implique qualquer entendimento a respeito de quais possibilidades se persegue, quais se abandona e quais motivos levam alguém a decidir por esta ou aquela possibilidade. No nível ôntico, porém, dá-se atenção aos desdobramentos cotidianos da condição ontológica.

Para que alguém se identifique com algumas possibilidades e rejeite outras ou "valorize" uma possibilidade e não outra, é preciso "encontrar-se numa situação na qual coisas e opções já fazem diferença” (Dreyfus, 1991, p. 168). Esta descrição se refere ao que Heidegger (1927/2006) chama de disposição afetiva. O ser humano não existe numa postura neutra diante do mundo. O homem está envolvido no mundo, interessado (ou desinteressado) pelos demais entes que encontra, ou seja, o ser humano é "determinado previamente em sua existência, de modo a poder ser tocado (...) pelo que vem ao encontro dentro do mundo. Esse ser tocado funda-se na disposição (...)” (Heidegger, 1927/2006, p. 196, itálicos no original).

Se o ser humano não se vinculasse afetivamente ao mundo, quer dizer, se não fosse disposto-no-mundo, “tocável” ou "afetável”, não poderia, por exemplo, eleger prioridades para sua vida, pois tudo que há no mundo se mostraria como sendo igual, não importando nem mais nem menos. A diferenciação entre o que interessa, atrai, importa ou não é possível em função da disposição afetiva. Essa afetividade, mantendo a coerência entre o pensamento heideggeriano e o frankleano, não é interiorizada, intrapsíquica; aquilo que afeta o homem é diferente dele: "Na disposição subsiste existencialmente um liame de abertura com o mundo, a partir do qual algo que toca pode vir ao encontro" (Heidegger, 1927/2006, p. 197, itálicos no original). O que vem ao encontro, então, já se mostra numa tonalidade afetiva e, assim, "torna possível um direcionar-se para...” (Heidegger, 1927/2006, p. 196, itálicos no original).

A disposição afetiva permite diferenciar as possibilidades, no que tange à sua relevância para cada um de nós; o modo de diferenciação é a valorização. Valoriza-se aquilo que, dentre as várias possibilidades "genéricas", nos "toca" de modo a se mostrar como algo a ser escolhido.

Kretschmer (1992) relaciona sentido e valores destacando o aspecto prático do afeto: "Sentido nós encontramos ao indagarmos para que algo serve, para o que algo é bom. Sentido da vida se nos depara no entendimento de que um valor, reconhecido como tal, nos afeta e insta ao desempenho de uma tarefa" (p. 71).

O desempenho de uma tarefa é uma possibili- dade do ser humano. Se o homem é instado a realizá-la, ele a valorizou, elegeu-a como sentido em meio a outras que ficaram em segundo plano. Sendo abertura-no-mundo, o homem tem a dimensão do possível, do poder-ser, como um constituinte de seu próprio ser. O que se é e o que se pode vir-a-ser estão juntos no ser humano.

Em seu ser, a presença já sempre se conjugou com uma possibilidade de si mesma (...) já sempre antecedeu a si mesma. A presença já está sempre 'além de si mesma', não como atitude frente aos outros entes que ela mesma não é, mas como ser para o poder-ser que ela mesma é (Heidegger, 1927/2006, p. 258-259, itálicos no original).

Pode-se entender que o ente que é-no-mundo já está vinculado ao que ele será, pois a antecipação em possibilidades lhe caracteriza existencialmente. Assim sendo, tem-se a condição para o que Frankl (1986) chama de noodinâmica.

Entendo que um dos atributos essenciais do ser humano consiste em achar-se num campo de tensão, entre os dois polos do ser e do dever-ser, em visar o sentido e os valores (...) a dinâmica que se estabelece no campo de tensão (...) denomina-se noodinâmica (Frankl, 1986, p.98).

Para que haja uma tensão entre ser e dever-ser, é preciso que o ser humano possa-ser algo que ele - ainda - não é. É preciso, portanto, que o homem tenha possibilidades de ser e, assim sendo, antecipe-se a si mesmo projetando-se nessas possibilidades. Em Heidegger, o poder-ser é um constituinte do ser humano e, como seu constituinte, o afeta (disposição afetiva), de modo que uma “tensão” seja possível.

Conforme observado acima, o ser humano como Dasein - não se limita ao "aqui e agora”; há como que um continuum entre ser e poder-ser, de modo que o ainda-não que pode vir-a-ser (futuro) está sempre "presente”. Em Frankl, o sentido é esse ainda-não, que orienta ("guia") o ser (verbo) humano, tensionando-o.

A realização da vontade de sentido não está livre de dificuldades. De acordo com Frankl (1986), pode haver dúvida quanto a qual é o sentido ou desesperança de encontrá-lo ou, ainda que se o identifique, pode haver empecilhos para sua realização. A essas condições, Frankl (1986) chama de frustração existencial. A frustração existencial é, então, a não realização de uma possibilidade (sentido) que se mostra como valorizada (disposição afetiva).

Para que alguém se frustre, é necessário querer que algo aconteça, estar na expectativa da realização do acontecimento, o que envolve uma determinada disposição afetiva. Expectativa diz respeito a um entendimento de como uma situação pode se desenrolar, ou seja possibilidades estão em jogo; logo, exige a consideração do momento atual (presente) e a de sua transformação (antecipação; futuro), com 
a realização daquilo que se espera (a possibilidade, aqui entendida como sentido). É necessário, portanto, que o homem possa projetar-se em possibilidades, antecedendo a si mesmo.

Então, para que se entenda o fenômeno da frustração existencial é preciso considerar que o ser humano não vive como um corpo (objeto) dentro de um espaço material (natureza). O ser do homem é um poder-ser que se projeta em possibilidades que encontra no mundo, porque mundo é um contexto de possibilidades que faz parte do modo de ser humano (ser-no-mundo).

Heidegger (1927/1993) observa que o Dasein não se limita a uma constatação fatual/posicional, pois a dimensão futura, o ainda-não (que pode ou não se realizar) faz parte de seu modo de ser.

Com base no modo de ser que se constitui através do existencial do projeto, a presença é sempre "mais" do que é fatualmente (...). No entanto, ela nunca é mais do que é faticamente, porque o poder-ser pertence essencialmente à sua facticidade. Também a presença, enquanto possibilidade de ser, nunca é menos, o que significa dizer que aquilo que, em seu poder-ser, ela ainda não é, ela é existencialmente (Heidegger, 1927/2006, p. 206, itálicos no original).

O homem não tem possibilidades, ele é suas possibilidades e por isso é que pode se frustrar, porque o possível não está num futuro distante; o possível está sempre presente. A afirmação de Heidegger é de que - no plano filosófico-existencial da reflexão - o ser humano não é mais nem menos, pois ele é tudo o que pode-ser. No plano psicológico, entretanto, é possível sentir-se "menos", ou seja, frustrar-se ou não realizar a possibilidade escolhida (valorizada). O possível é um constituinte do ser humano e como tal o afeta ("toca-o"), faz diferença, tensiona-o. O possível é agora. Fazendo diferença “agora”, a dimensão do possível, do poder-ser, pode orientar a vida cotidiana, na forma de sentido de vida, desde que se entenda que o sentido é uma possibilidade valorizada.

A frustração é uma repercussão psicológica de algo que alguém - possivelmente - é. Se tenho o desejo e a expectativa de que algo se realize e ajo, a fim de realizar minha expectativa, no âmbito da possibilidade já vivencio essa realização, cujo eventual fracasso me frustra. Ser-possível não quer dizer que será de fato, mas como o poder-ser faz parte do modo de ser humano, o possível já repercute na atualidade das pessoas.

\section{Considerações Finais}

Noções da Analítica do Dasein podem ser empregadas para que se entenda a possibilidade da psicologia do sentido da vida de Frankl. Em outras palavras: a descrição do modo de ser humano elaborada por Heidegger, permite que se entenda quais características do ser humano estão envolvidas ou são a condição de possibilidade da busca por sentido. Além disso, essa aproximação entre a Analítica e a Logoterapia enseja a discussão a respeito da apropriação de temas filosóficos pela psicologia.

De acordo com a reflexão elaborada neste estudo, a filosofia de Heidegger pode ser apropriada pela psicologia, tendo como referência a Logoterapia frankleana, da seguinte maneira: Heidegger afirma que o Dasein está em relação com seu próprio ser; a partir dessa característica existencial, pode-se pensar que apenas o ente que tem relação consigo mesmo pode buscar sentido para sua vida, uma vez que a autorrelação gera o questionamento da sua própria vida e a responsabilidade por seu encaminhamento. A relação que o Dasein tem com seu próprio ser não é interiorizada, ela ocorre no mundo na forma de ocupação com entes não humanos e preocupação com entes humanos; é a partir dessas relações que o Dasein se projeta em possibilidades, as relações mostram possibilidades. Sendo assim, estão dadas as condições para que o ser humano transcenda a si mesmo, valorizando algumas possibilidades, cuja processo de realização constitui o(s) sentido(s) de seu viver.

O ser humano é um ente que se define e se redefine em função das possibilidades nas quais se projeta, a partir das ocupações e preocupações que encontra no mundo. Desse modo, em seu ser há indeterminação e liberdade (nunca absolutas, é bom lembrar). Aqui encontra-se uma condição para a afirmação de Frankl de que o sentido muda de pessoa para pessoa e a cada momento, numa tensão entre ser e vir-a-ser.

Se o Dasein heideggeriano está sempre numa determinada disposição afetiva, de modo que os entes podem "tocá-lo" de alguma maneira, pode, então, o ser humano, eleger possibilidades, valorizando-as.

A noção de cura como integração entre anteceder-se, facticidade e ser-junto é entendida por Borges-Duarte (2010) como "tensão vital”; já em Frankl, a tensão é relativa ao sentido, que pode ser pensado, em paralelo com a cura, como antecipação em algum sentido (futuro), a partir de um contexto valorativo (passado), e relação com os demais entes (presente), conforme o sentido projetado.

\section{Referências}

Blattner, W. (2006). Heidegger's Being and Time, A Reader's Guide. New York: Continuum, 2006.

Borges-Duarte, I. (2010). A fecundidade ontológica da noção de cuidado: de Heidegger a Maria de Lourdes Pintasilgo. Ex Aequo, 21, 115-131.

Cerbone, d. R. (2009). Heidegger: a guide for the perplexed. London: Continuum.

DeLancey, C. (2006). Action, the scientific worldview, and being-in-the-world. Em H. Dreyfus \& M. Wrathall, $A$ Companion to Phenomenology and Existentialism (pp. 356-376). Oxford: Blackwell Publishing. 
Dreyfus, H. (1991). Being-in-the-world: a commentary on Heidegger's Being and Time, Division I. Cambridge: MIT Press.

Etcheverry, J. A. (1990). Viktor Frankl y la Logoterapia. Buenos Aires: Almagesto.

Frankl, V. (1986). Psicoterapia e sentido da vida. São Paulo: Quadrante.

Frankl, V. (1989). Um sentido para a vida. Aparecida: Santuário.

Frankl, V. (1993). Em busca de sentido. Petrópolis: Vozes; São Leopoldo: Sinodal.

Frankl, V. (2000). Recollections. Cambridge: Perseus Publishing.

Frie, R. (1999). Interpreting a misinterpretation: L. Binswanger and M. Heidegger. Journal of the British Society for Phenomenology, 30, 244-257.

Heidegger, M. (2001). Seminários de Zollikon. Petrópolis: Vozes/EDUC/ABD. (Originalmente publicado em 1987).

Heidegger, M. (2006). Ser e Tempo. Petrópolis: Vozes; Bragança Paulista: São Francisco (Originalmente publicado em 1927).

Heidegger, M. (2012). Os problemas fundamentais da fenomenologia. Petrópolis: Vozes.

Horrigan-Kelly, M., Millar, M. \& Dowling, M. (2016). Understanding the key tenets of Heidegger's philosophy for interpretive phenomenological research. International Journal of Qualitative Methods, Jan-Dez, 1-8.

Kretschmer, W. (1992). Valor do eu e sentido da vida. Em Dar sentido à vida, vários autores (pp. 63-73). Petrópolis: Vozes; São Leopoldo: Sinodal.

Längle, A. (1992). Viver com sentido. Petrópolis: Vozes; São Leopoldo: Sinodal.

Letteri, M. (2009). Heidegger and the question of psychology. Amsterdam: Rodopi.

Mulhall, S. (2013). The Routledge guidebook to Heidegger's Being and Time. New York: Routledge.

Polt, R. (1999). Heidegger: an introduction. Ithaca: Cornell University Press.

Safranski, R. (2005). Heidegger, um mestre da Alemanha entre o bem e o mal. São Paulo: Geração Editorial.

Sheehan, T. (2014). What, after all, was Heidegger about? Continental Philosophy Review, 47(3-4), 249-274.

Vattimo, G. (1987). Introdução a Heidegger. Rio de Janeiro: Edições 70. (Originalmente publicado em 1971).
Marcelo Vial Roehe é Graduado em Psicologia pela Universidade Federal do Rio Grande do Sul, com Mestrado em Psicologia pela Pontifícia Universidade Católica do Rio Grande do Sul e Doutorado em Psicologia pela Universidade Federal do Rio Grande do Norte. Professor da Universidade Federal do Sul e Sudeste do Pará, Marabá, Universidade Federal do Sul e Sudeste do Pará (UNIFESSPA). Email: mvroehe@gmail.com

Recebido em 15.04.2018

Primeira Decisão Editorial em 27.07.2018

Aceito em 22.08.2018 